Cómo citar este artículo: Battaner Arias, Paz y López Ferrero, Carmen (2019). "La flexibilidad como propuesta normativa a la diversidad lingüística y dialectal. Perspectivas desde la Real Academia Española (RAE)". Journal of Spanish Language Teaching 6 (2), pp. 106-118.

DOI: https://doi.org/10.1080/23247797.2019.1668180

\title{
LA FLEXIBILIDAD COMO PROPUESTA NORMATIVA A LA DIVERSIDAD LINGÜÍSTICA Y DIALECTAL. PERSPECTIVAS DESDE LA REAL ACADEMIA ESPAÑOLA (RAE)
}

\author{
Paz Battaner Arias (Real Academia Española) \\ Carmen López Ferrero (Universitat Pompeu Fabra)
}

\begin{abstract}
Resumen
La visión de la lengua española como una lengua policéntrica ha cuajado en el concepto de panhispanismo y de su puesta en práctica por la Real Academia Española (RAE) y por la Asociación de Academias de la Lengua Española (ASALE). La extensión geográfica del español es causa de su diversidad lingüística. Respetar esa diversidad y a la vez mantener la unidad de la lengua ante el estallido de las facilidades de la comunicación interpersonal en el siglo XXI impulsó a la RAE a transitar firmemente en la dirección panhispánica. Será objeto de atención en el presente informe señalar los retos que afronta esta política en la tercera década del siglo XXI y en qué iniciativas se plasma la filosofía normativa consensuada por la Academia a través de sus últimas publicaciones. La repercusión o impacto real de sus recursos, gramática, diccionario y otros, se sustanciará a través de las consultas en abierto que reciben, de las estadísticas que se realizan sobre ellas, tanto de número como de países desde las que tienen lugar, de su reflejo en algunos manuales de ELE y en los cursos de formación del profesorado especializado.
\end{abstract}

Palabras clave

Real Academia Española, diversidad lingüística, variación dialectal, policentrismo, política panhispánica.

\begin{abstract}
The view that Spanish is a polycentric language is rooted in the concept of Pan-Hispanism and its implementation by the Real Academia Española (RAE) and the Asociación de Academias de la Lengua Española (ASALE; Association of Academies of the Spanish Language). The geographical spread of Spanish is the underlying cause of such diversity. Respecting this diversity whilst simultaneously maintaining the unit of the Spanish language in the face of increasingly accessible interpersonal communication has driven the RAE to move firmly towards the pan-Hispanic policy. In the present report we point out the challenges this policy faces in the third decade of the $21^{\text {st }}$ century and which initiatives embody the normative philosophy agreed by the Academy in their more recent publications. The repercussions or true impact of its resources, grammar, dictionary amongst other resources, are supported by the queries that the RAE receives, the statistics it draws from them, both in terms of the number of queries and their country or origin, through its evidence in some Spanish Language Teaching textbooks and in the training courses of specialized teachers.
\end{abstract}

Keywords

Royal Spanish Academy, linguistic diversity, dialect variation, polycentricism, Pan-hispanic language policy 
Cómo citar este artículo: Battaner Arias, Paz y López Ferrero, Carmen (2019). "La flexibilidad como propuesta normativa a la diversidad lingüística y dialectal. Perspectivas desde la Real Academia Española (RAE)". Journal of Spanish Language Teaching 6 (2), pp. 106-118.

DOI: https://doi.org/10.1080/23247797.2019.1668180

\section{Introducción. El español como lengua policéntrica: el panhispanismo}

Un ejemplo extraído de una de las aplicaciones más usadas en la telefonía móvil de hoy en día, el asistente virtual de Apple, denominado "Siri", puede servir de arranque e ilustración de este informe sobre el impacto que el español como lengua panhispánica está teniendo en la actual sociedad de la información y de la comunicación:

“Oye, Siri, ¿de quién es la voz de tu versión española?

$[\ldots]$

- Siri: ... En español tienes cuatro opciones para elegir: español de España, de Chile, de México y de Estados Unidos...

$[\ldots]$

- ¿Cuál es la voz más solicitada en español?

- La mayor parte de los hispanohablantes seleccionan la voz femenina del español de España; no solo en España, también en países como Argentina, Colombia, Chile o México, donde muchos prefieren escuchar a "la gallega", como ellos la llaman."

Cruzat $(2018,84)$

Como se observa en el ejemplo, el español hoy, además de mantener su origen ligado a su denominación internacional, se materializa en una voz femenina y presente en varios focos de irradiación, una lengua, pues, policéntrica. La calificación de "policéntrica" surgió por primera vez a mediados de los años 60 del pasado siglo a raíz del Proyecto de estudio coordinado de la norma lingüística culta de las principales capitales de Iberoamérica y de la Península Ibérica, propuesto por el entonces presidente de la Comisión de Lingüística y Dialectología Iberoamericanas, Juan M. Lope Blanch ${ }^{1}$ (Lope Blanch 1973, 1986). Desde entonces hasta ahora, la irradiación del modo más apreciado de uso de la lengua en cada capital estatal se ve altamente reforzada por la capacidad de difusión actual de los medios de comunicación y por los recursos lingüísticos en abierto que la Real Academia Española (RAE) ofrece tanto a los hispanohablantes como a quienes aprenden español como segunda lengua (L2) o lengua extranjera (ELE).

Ante la variación y evolución de la lengua, sigue totalmente vivo hoy en día el programa de la RAE desde 1723: "no enmendar ni corregir, sino solo explicar, apreciar, cuestionar voces, frases, locuciones", programa que supo actualizar Andrés Bello en su Gramática de la lengua castellana destinada al uso de los americanos (1847 [1988]). Así pues, la política lingüística desarrollada por la RAE ha sido siempre sensible a las necesidades manifiestas en las repúblicas americanas desde que en Madrid se entendió bien el Prólogo de la Gramática de Bello, manual pensado y realizado, como se destaca en el título, para "uso de los americanos".

El "panhispanismo" y lo "panhispánico" se apoyan en la gran comunidad de hablantes de la lengua española, buscando el consenso de los cultos. Su acuñación y su uso literal en la corporación no se produce hasta la última década del siglo $\mathrm{XX}$, bajo la dirección de Víctor García de la Concha (1998-2010). El compromiso que la RAE y la Asociación de Academias de la Lengua Española (ASALE) contraen con el espíritu panhispánico se hace explícito a partir del XII Congreso de la Asociación en San Juan de Puerto Rico en 2002, en boca del director de la Academia puertorriqueña, José Luis Vega (en López Morales 2016, 728):

"Debo destacar, por su significación, los informes presentados en este Congreso -reproducidos en este volumen- sobre las obras panhispánicas con las que todos estamos comprometidos: sobre el Diccionario panhispánico de dudas, en este momento en que escribo, felizmente terminado"2

En este XII Congreso de la Asociación de Academias se presentaron los proyectos de la ortografía consensuada y del diccionario de dudas, contempladas estas desde todos los puntos geográficos en donde se producen (lo que diferencia este diccionario del Diccionario de dudas de Manuel Seco, cuya primera edición es de 1961 [2011]). La primera publicación que lleva el adjetivo "panhispánico" en el título, por tanto, es el Diccionario panhispánico de dudas (DPD 
Cómo citar este artículo: Battaner Arias, Paz y López Ferrero, Carmen (2019). "La flexibilidad como propuesta normativa a la diversidad lingüística y dialectal. Perspectivas desde la Real Academia Española (RAE)". Journal of Spanish Language Teaching 6 (2), pp. 106-118.

DOI: https://doi.org/10.1080/23247797.2019.1668180

2005), obra conjunta de la RAE y de la ASALE; y la última, a finales de 2018 cuando se publica en Madrid el Libro de estilo de la lengua española, cuyo subtítulo da un paso más y se anuncia según la norma panhispánica. Se expresa ahora claramente, por primera vez, en la segunda década de este siglo XXI, la atención por la "norma panhispánica".

El panhispanismo de la RAE -y de la ASALE - reclama una normativa flexible. En el estudio que López Morales (2016) lleva a cabo sobre la gestación de la ASALE (en 1951) y los resúmenes de los programas de los catorce Congresos de la Asociación de Academias entre 1951 y 2011, el leitmotiv es la unidad de la lengua. Esta cuestión es vista desde sus peligros: la coexistencia de otras lenguas, la invasión de anglicismos, los neologismos, la falta de una enseñanza de calidad, sobre todo. La profundización en el estudio de la lengua y la flexibilidad como propuesta normativa desde entonces puede reseguirse a través de varias iniciativas: en el contenido de los prólogos del DPD (2005), de la Nueva Gramática de la Lengua Española (NGLE RAE y ASALE 2009), de la Ortografía (RAE y ASALE 2010b), de la Fonética y Fonología (FyF 2011) o del Diccionario de la lengua española (DLE 2014); y en las consultas y explicaciones que se ofrecen en el servicio Español al día de la RAE. Todos estos recursos están disponibles en la red para quien quiera o necesite consultarlos. Lo inteligente de la norma panhispánica que en ellos se propone es orientar sobre el uso del español sin exigencia y con un grado muy alto de variación adaptado a diferentes modalidades diatópicas y diafásicas.

Esta actitud y su impacto son los que abordamos en los apartados que siguen: primero, en la forma como se recoge el panhispanismo en las obras y recursos de la RAE -gramática, ortografía, pronunciación, diccionarios, de dudas y general-, con ejemplos de su atención (§2); segundo, en cómo la RAE mide lo "panhispánico" a través de los datos estadísticos mensuales de uso de las herramientas disponibles en su página web y a través de las consultas en abierto que recibe (\$3) desde países de lengua castellana y de lenguas muy diferentes; tercero, en la forma como influye esta política panhispánica en distintos ámbitos educativos y sociales: en la elaboración de manuales de enseñanza del español como lengua extranjera (ELE), en másteres de profesorado de ELE, en medios de comunicación (§4). Cerramos esta reflexión apuntando algunos de los retos a los que se ha de enfrentar el panhispanismo desde la Real Academia Española (§5) en la tercera década de este siglo.

\section{La orientación panhispánica en los recursos de la RAE: criterios y ejemplos de variación}

La voluntad de destacar la norma consensuada entre los distintos centros de referencia del español, su sentido utilitario, de servicio a las "generaciones vivas", y la necesidad de que sean los usos vigentes, extendidos y frecuentes, los que se aconsejan o recomiendan a los hablantes se refleja en las presentaciones que ofrece la RAE de sus distintas obras académicas -impresas y accesibles en línea-, concretamente de estas cinco: el DPD (2005), la NGLE (2009) -también el Manual y la Nueva gramática básica-, la FyF (2011), la Ortografía (2010) y el DLE (2014) (Véase el listado de recursos en http://rae.es/recursos). .

En la presentación del $D P D$ (2005) se detalla que esta obra responde a una necesidad recogida por las Academias de que la norma "no es algo decidido y arbitrariamente impuesto desde arriba", sino el consenso de la comunidad al seguir los modelos de la escritura o del habla considerados cultos. En la explicación razonada, se valora como un instrumento que ha de ser eficaz, por presentar el uso actual, sin elevar a norma expresiones que tuvieron prestigio en otros momentos. Los criterios de vigencia, extensión y frecuencia son los aconsejados o preferidos. Dos ejemplos bajo la letra $c$ muestran la mirada panhispánica y la aplicación de estos criterios:

Cuauhtémoc. Nombre de pila masculino, tomado del que tenía el último rey azteca de México, y nombre de una localidad del estado mexicano de Chihuahua. Debe escribirse con tilde por ser voz llana terminada en consonante que no es ni $-n$ ni $-s\left(\rightarrow \underline{\text { TILDE }^{2}}, \underline{1.1 .2}\right)$ : «La principal zona 
Cómo citar este artículo: Battaner Arias, Paz y López Ferrero, Carmen (2019). "La flexibilidad como propuesta normativa a la diversidad lingüística y dialectal. Perspectivas desde la Real Academia Española (RAE)". Journal of Spanish Language Teaching 6 (2), pp. 106-118.

DOI: https://doi.org/10.1080/23247797.2019.1668180

manzanera del país se ubica en los municipios de Cuauhtémoc y Guerrero» (Estatal @ [Méx.] 20.9.04). No es correcta la grafía Cuahutémoc.

cuatrimotor. '[Avión] provisto de cuatro motores': «El viaje a Honduras se realizó en un cuatrimotor» (País [Esp.] 15.9.77). En algunos países de América, se usa con frecuencia la variante cuadrimotor: "Un cuadrimotor a hélice, dotado de ultramodernos equipos electrónicos para observación e información»(Tiempo[Col.] 16.4.94); o bien se emplea el sinónimo tetramotor: «Entramos en el vientre del espléndido tetramotor subiendo por una escalera móvil» (Tibón Aventuras [Méx. 1986]).

En cuanto a la NGLE (2009), se presenta en los siguientes términos en la web de la RAE:

- $\quad$ panhispánica, ya que refleja la unidad y la diversidad del español, y muestra el español de todas las áreas lingüísticas con sus variantes geográficas y sociales;

- descriptiva, porque expone las pautas que conforman la estructura del idioma y analiza de forma pormenorizada las propiedades de cada construcción;

- normativa, puesto que recomienda unos usos y desaconseja otros.

Las versiones Manual (RAE y ASALE 2010a) y Básica (RAE y ASALE 2011) de esta NGLE, aunque más esquemáticas y pedagógicas, no omiten ningún aspecto de la información normativa de la obra de referencia: ,-se ha entendido que estos aspectos del análisis gramatical interesan a todos los hablantes. Ilustra estas opciones el siguiente ejemplo a propósito de la variación entre el pretérito indefinido y el pretérito perfecto compuesto (véase Figura 1 a continuación):

23.7c En otros países (México, muchos de los centroamericanos y varios de los del área caribeña, entre los que está Venezuela), la oposición entre CANTÉ y HE CANTADo es más propiamente aspectual que temporal. El pretérito perfecto simple se usa en esos casos para referirse a acciones acabadas en el pasado, mientras que el pretérito perfecto compuesto se reserva para referirse a acciones que continúan en el presente. Así, en Hoy estuvo más tranquilo (Excélsior 21/1/1997), estuvo se construye en pretérito perfecto simple porque la situación de la que se habla ha concluido. En otras áreas, como el español de Chile o de gran parte de la Argentina (con las excepciones reseñadas arriba), la oposición se neutraliza a favor del pretérito perfecto simple, con un uso semejante al que se da en el noroeste de España y en las islas Canarias. En estas zonas, el pretérito perfecto simple sustituye al compuesto, con independencia del valor temporal o aspectual de la acción. En el español costeño peruano y el andino boliviano suele darse la neutralización de la oposición en sentido contrario al descrito anteriormente, ya que es el pretérito perfecto compuesto el que sustituye al simple. Esta compleja situación condiciona la distribución de uso que se hace en los apartados siguientes, de modo que, en las zonas en las que el sistema propio funciona de manera distinta a la descrita, los valores atribuidos a HE CANTADO se expresan de forma habitual mediante CANTÉ.

Figura 1. Extracto de la NGLE $(2009,1722)$.

Aspira, por tanto, esta $N G L E$ a convertirse en la gramática del español de todo el mundo. Guían este planteamiento dos ideas, recogidas en su Prólogo (NGLE 2009, XXXIX-XLVIII):

a) la norma del español tiene hoy carácter policéntrico, no hay ninguna variedad de un país hispánico que se pueda presentar como modelo de uso; la NGLE intenta mostrar lo que hay de común y lo que hay de variedad, lo que fortalecerá la unidad de la lengua;

b) la norma, pues, es tratada como una variable de la descripción, unas construcciones poseen prestigio, otras no; unas se acercan a lo coloquial, otras a los registros elaborados o formales; forman parte de la lengua estándar o están restringidas a algún tipo de discurso especializado. Las recomendaciones normativas que se hacen en ella son juicios de valor 
Cómo citar este artículo: Battaner Arias, Paz y López Ferrero, Carmen (2019). "La flexibilidad como propuesta normativa a la diversidad lingüística y dialectal. Perspectivas desde la Real Academia Española (RAE)". Journal of Spanish Language Teaching 6 (2), pp. 106-118.

DOI: https://doi.org/10.1080/23247797.2019.1668180

que reflejan el consenso implícito extraído de "un sistema compartido por muchos millones de hablantes".

En la $N G L E$ (2009) se concede mayor atención a la variación geográfica que a las variaciones históricas y socioculturales. Sus recomendaciones normativas cuentan con el respaldo de la institución internacional ASALE, "sustentado en la autoridad que los hispanohablantes le reconocen en lo relativo a la fijación de la norma". A veces se exponen al principio de los capítulos teorías encontradas en algunos de los puntos que se abordan, pero la NGLE es flexible en este sentido: "Sería, sin embargo, poco prudente pedir a las Academias que se sitúen al margen - cuando no por encima-de los foros científicos en los que hoy se discuten con intensidad numerosas cuestiones polémicas." (NGLE 2009, XLVI). En consecuencia, esos problemas exclusivamente se presentan como controvertidos.

En cuanto a la $F y F$ (2011) y el DVD Las voces del español (RAE y ASALE 2011), como tercer volumen de la $N G L E$, se insertan también en la serie de obras consensuadas de carácter panhispánico que las Academias vienen desarrollando desde hace diez años. No se comenta en el Prólogo si hay unos puntos comunes y otros variables, lo dirá quizá en el contenido de los capítulos; sin embargo, en la descripción, y en el DVD, hay muestras de las diferentes realizaciones de las principales modalidades dialectales fónicas del mundo hispánico

La Ortografía de la lengua española es también un trabajo conjunto de 22 Academias; el ideal ortográfico panhispánico se muestra ya a finales de los años 90 desde la Ortografía de 1999, consensuada y presentada en el Congreso Internacional de la Lengua Española de Chile. Responde, pues, al examen pormenorizado que todas las Academias hicieron de ella. Y en 2007, en Medellín, se llegó a pedir una nueva redacción con revisión, eliminación razonada de las normas potestativas introducidas en 1999 y coherencia en todas las otras obras de las Academias. En la presentación de la actual Ortografía (RAE y ASALE 2010b) se destaca la obligación de buscar la unidad escrita del idioma para que los cambios continuos que experimenta el español como lengua viva no rompan la unidad que se mantiene en el "ámbito hispánico" pues la ortografía es un factor de unidad y contención de muchas variables. Una advertencia y el detalle "panhispánico" de la denominación de la letra $y$ sirve de ejemplo (véase Figura 2 a continuación): 
Cómo citar este artículo: Battaner Arias, Paz y López Ferrero, Carmen (2019). "La flexibilidad como propuesta normativa a la diversidad lingüística y dialectal. Perspectivas desde la Real Academia Española (RAE)". Journal of Spanish Language Teaching 6 (2), pp. 106-118.

DOI: https://doi.org/10.1080/23247797.2019.1668180

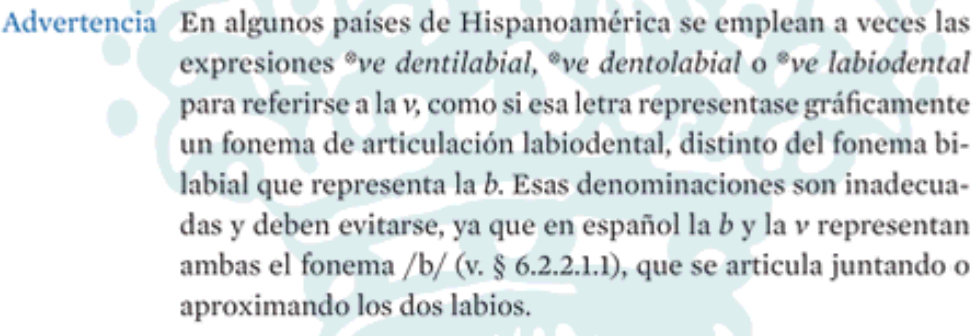

Advertencia En algunos paises de Hispanoamérica se emplean a veces las expresiones "ve dentilabial, ${ }^{\circ}$ ve dentolabial o ${ }^{*}$ ve labiodental para referirse a la $v$, como si esa letra representase gráficamente un fonema de articulación labiodental, distinto del fonema bilabial que representa la $b$. Esas denominaciones son inadecuadas y deben evitarse, ya que en español la $b$ y la $v$ representan ambas el fonema /b/ (v. § 6.2.2.1.1), que se articula juntando o aproximando los dos labios.

\section{- $y$}

Hasta el último tercio del siglo XIX, las ortografías académicas otorgaban a esta letra el nombre de $i$ griega (escrito, en un principio, $y$ griega), aunque durante un tiempo fue llamada también $y$ consonante, por oposición a la $i$ vocal. El nombre tradicional de $i$ griega, reflejo de su origen y empleo inicial en préstamos del griego, es descendiente directo del nombre latino de este signo. No obstante, en 1869, el diccionario académico registra para este grafema el nombre ye, por aplicación del patrón denominativo que siguen la mayoría de las consonantes. Este ha sido el nombre académico preferente para esta letra hasta finales del siglo $\mathrm{xx}$, lo que explica su implantación en el uso, especialmente en el español americano. Aunque las obras académicas más recientes volvieron a señalar como preferente el nombre tradicional de $i$ griega, hoy se considera preferible proponer el nombre ye como el único recomendado para todo el ámbito hispánico, por ser más simple y distinguirse directamente, sin necesidad de especificadores, del nombre de la vocal $i$.

Figura 2. Extracto de la Ortografía $(2010,71)$.

La edición escolar Ortografía básica (2012) mantiene la política panhispánica, pero, a diferencia de la Ortografía (2010), no busca ofrecer exhaustividad, sino una selección de las normas por su importancia.

También el DLE (RAE y ASALE 2014), la última obra de referencia lexicográfica de la RAE y ASALE que recogemos en este informe, es el resultado de la colaboración de todas las Academias, cuyo propósito es definir el léxico general utilizado en España y en los países hispánicos. Se dirige, fundamentalmente, a hablantes cuya lengua materna es el español, quienes encontrarán en él recursos suficientes para descifrar textos escritos y orales. Continuamente van llegando a la RAE, organismo del que salen las primeras propuestas, sugerencias de incorporaciones de nuevo vocabulario, de adiciones o de enmiendas: la Unidad Interactiva del Diccionario (UNIDRAE) ${ }^{3}$ de la página www.rae.es es el servicio que recoge estas sugerencias y las orienta hacia las diferentes comisiones de académicos de número, que trabajan todos los jueves en la RAE. Estas actualizaciones continuas del diccionario usual de la RAE-ASALE representan un flujo de trabajo entre las comisiones de España y las Academias americanas.

Incluimos a continuación varios ejemplos de esta forma de proceder, pertenecientes a la última actualización (diciembre de 2018) del DLE en línea, versión 23.2. Son muestras de la atención a varias marcas diatópicas, en distintos contextos (véase Tabla 1 a continuación): 
Cómo citar este artículo: Battaner Arias, Paz y López Ferrero, Carmen (2019). "La flexibilidad como propuesta normativa a la diversidad lingüística y dialectal. Perspectivas desde la Real Academia Española (RAE)". Journal of Spanish Language Teaching 6 (2), pp. 106-118.

DOI: https://doi.org/10.1080/23247797.2019.1668180

Tabla 1. Marcas diatópicas actualizadas en diciembre de 2018 en el DLE.

$\tilde{\mathbf{n}}^{\mathrm{n}} \mathbf{c}^{2}$, ca. [Adición de artículo]. adj. coloq. R. Dom. Dicho de una persona: Que ha perdido un brazo o una mano, o los tiene inutilizados. U. t. c. s.

$\tilde{\mathbf{n e c o}}^{2}$, ca. [Adición de etimología de artículo]. (Cf. ñoco y ñuco falto de un miembro, dedo, mano, del área del Caribe).

neco $^{1}$, conejo

pachón, na. ... [Adición de acepción]. $\odot$ m. 3 bis. Guat. Recipiente cilíndrico destinado a transportar líquidos.

quechuista. [Adición de artículo]. m. y f. Especialista en la lengua y cultura quechuas.

quichuista. m. y f. [Enmienda de acepción]. Ec. quechuista.

radicheta. [Adición de artículo]. f. Arg. y Ur. Planta de hasta $1,50 \mathrm{~m}$ de altura, variedad de la achicoria, de hojas comestibles.

radicheta. [Ádición de etimología de artículo]. (Del it. radicchietto, dim. de radicchio 'achicoria').

sojero, ra. [Adición de artículo]. adj. 1. Arg., Par. y Ur. Perteneciente o relativo a la soja. \| 2. Arg., Par. y Ur. Que se dedica al cultivo o a la comercialización de la soja. Apl. a pers., u. t. c. s. m. y f. Apl. a empresa, u. t. c. s. f.

tribunalicio, cia. [Adición de artículo]. adj. Arg., Chile, C. Rica, Cuba, Guat., Méx., Par., Perú, Ur. y Ven. Perteneciente o relativo a los tribunales.

FRENTE A:

tronco, ca. ... [Adición de acepción]. • m. y f. 1 bis. coloq. Esp. U. como apelativo para designar a un amigo o compañero.

Como se observa, hay casos de coloquialismos, ñeco; de objetos domésticos, pachón; de derivados propios, sojero, tribunalicio; de denominaciones que no figuraban aún, quechuista y enmienda en la forma quichuista, antes como de Ecuador y ahora se remite a quechuista, especialista y sin marca diatópica. Por el contrario, se añade la acepción con marca de España en tronco. Estas actualizaciones son una muestra también de la flexibilidad de la propuesta normativa, como lo es la gestión que se lleva a cabo en las consultas del Español al día de la RAE.

\section{El panhispanismo de la RAE en las consultas en línea}

La RAE no solo tiene sus recursos abiertos en línea, sino que también presta atención al impacto de su política panhispánica. Lo sigue a través de los datos estadísticos mensuales de uso de su página web y a través de las consultas que se reciben.

Sobre el seguimiento de los recursos de la RAE se elaboran unas estadísticas mensuales que dan datos cuantitativos y cualitativos de ello. Por ejemplo, de su alcance en febrero de 2019, ofrecemos los diez países que más consultas realizan al $D L E$, que coinciden con ser de español como lengua nativa (véase Figura 3 a continuación): 
Cómo citar este artículo: Battaner Arias, Paz y López Ferrero, Carmen (2019). "La flexibilidad como propuesta normativa a la diversidad lingüística y dialectal. Perspectivas desde la Real Academia Española (RAE)”. Journal of Spanish Language Teaching 6 (2), pp. 106-118.

DOI: https://doi.org/10.1080/23247797.2019.1668180

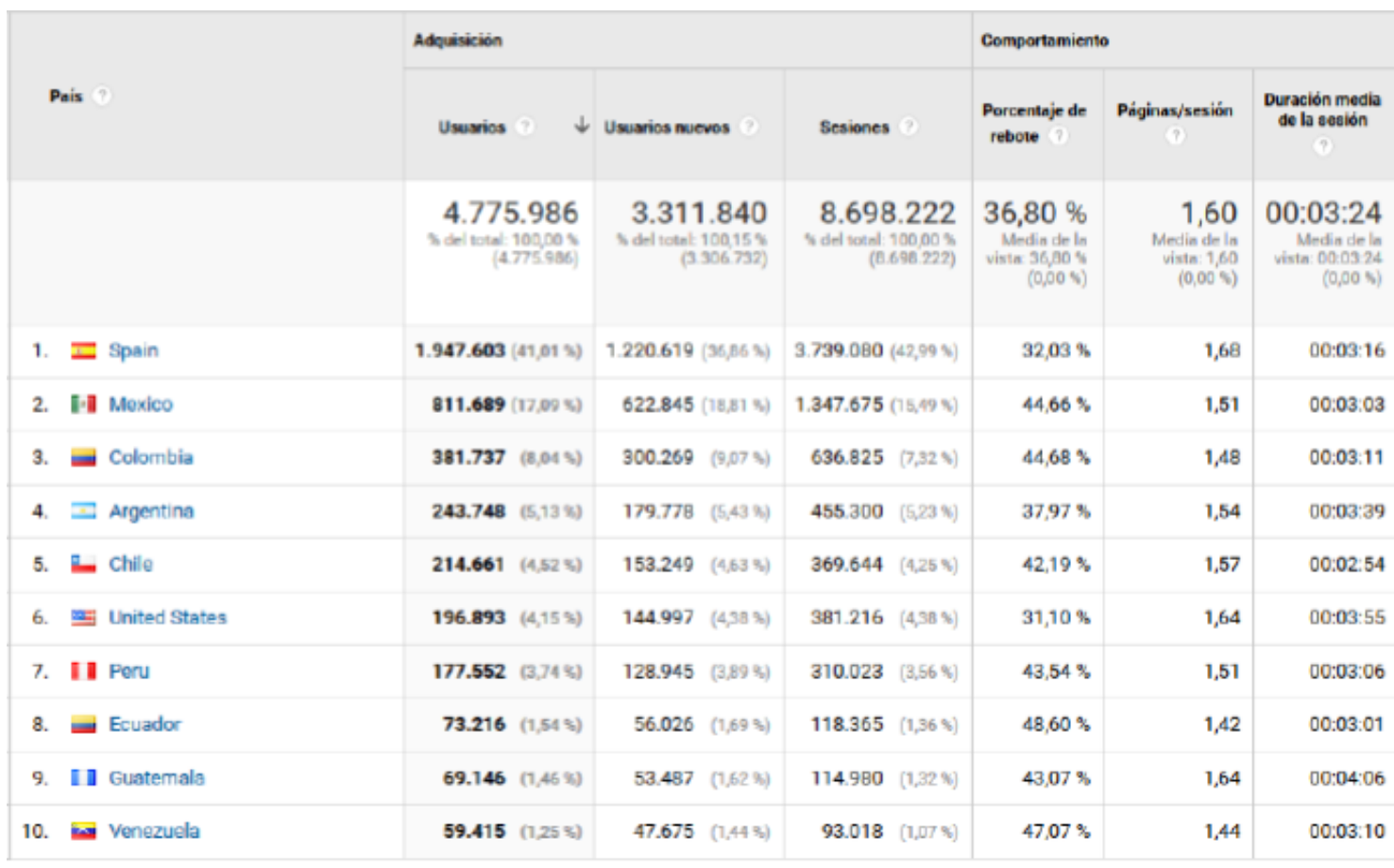

Figura 3. Información geográfica de las consultas al DLE, estadísticas de febrero de 2019

El impacto también es manifiesto en el detalle del tipo de consultas realizadas. Se pueden saber, por ejemplo, todas las voces consultadas desde los Estados Unidos, país considerado como de hispanohablantes, al DLE en línea, durante el mes de marzo de 2019. Los lemas que en diferentes formas han recibido atención entre las más de 3.500 .000 visitas que se han hecho son dar (4.448), estar (4.094), caseto (3.922), orgullo (3.704), tener (3.520), hasta (3.520) entre las voces más frecuentes; y leonino (3.376), *calectable (3.310), discinesia (3.269), asana (3.213), orzar (3.211) y ontología (3.179) entre voces cuyo significado muy probablemente se desconozca. Calectable no se encuentra en el diccionario y en tales casos se tienen en cuenta estas búsquedas fallidas para ser estudiadas metódicamente por las diferentes comisiones académicas. Si atendemos a las voces consultadas desde Francia durante ese mismo mes de marzo de 2019, entre un total de más de 50.000 consultas (mucho menores por ser país de español como lengua extranjera), se recogen por ejemplo, feminismo (4.798), mito (1.140), ceroma (1.017), letraherido (1.013) idiopático $(1,009)$ y voces que pueden presentar alguna dificultad gramatical para un extranjero como preposiciones, de, a, hasta, formas de verbos irregulares y usuales como ir, haber, ser, poder, que han recibido entre las 1.370 consultas y las 1.151 del último. En las cerca de 50.000 voces recogidas desde Rusia también en el mismo periodo, se encuentran coincidencias, como feminismo (5.151), muy posiblemente por la conmemoración del 8 de marzo y ya, en menor número, esa voz conlleva también la búsqueda de machismo (961); otros ejemplos de consulta desde Rusia son bruxismo (933), apropincuarse (918), hipotermia (829) y ataché (827).

Los datos estadísticos analizados mes a mes proporcionan conocimiento sobre el seguimiento del léxico por los hablantes de países de lengua castellana y de los países en que esta lengua es objeto de aprendizaje o de estudio. Se tiene recogido un total de doscientos setenta países desde los que en algún momento se hicieron consultas a la página www.rae.es.

Esta información cuantitativa y, en parte también, cualitativa sirve de constatación de la política lingüística que se lleva a cabo a través de los trabajos generados por la RAE y ofrecidos en abierto. Las consultas que reciben otros recursos académicos, Nuevo diccionario histórico, Diccionario del estudiante; o bien los corpus lingüísticos, con preferencia del CREA y a 
Cómo citar este artículo: Battaner Arias, Paz y López Ferrero, Carmen (2019). "La flexibilidad como propuesta normativa a la diversidad lingüística y dialectal. Perspectivas desde la Real Academia Española (RAE)”. Journal of Spanish Language Teaching 6 (2), pp. 106-118.

DOI: https://doi.org/10.1080/23247797.2019.1668180

continuación los CORDE, CORPES XXI y CDH, dan datos fehacientes de su influencia. Hoy muchos de estos recursos están conjuntados en la plataforma ENCLAVE, https://enclave.rae.es/.

Además, en el servicio denominado Español al día que la RAE pone a disposición de los hablantes de español y de las personas que lo están aprendiendo como L2 o ELE, se van recibiendo consultas cuyo alcance y respuestas reflejan la flexibilidad normativa de la política panhispánica de esta institución. Se reciben en este servicio más de 200 consultas diarias aproximadamente. Presentamos a continuación solo, por cuestión de espacio, dos ejemplos de algunas de las preguntas llegadas a Español al día de interesados no nativos ${ }^{4}$ : el primer ejemplo de un ingeniero húngaro es representativo de la necesidad de adquirir formas léxicas coloquiales en el país hispanohablante visitado; el segundo de un estudiante brasileño atiende a la prosodia de las letras (véanse las Figuras 4 y 5 a continuación).

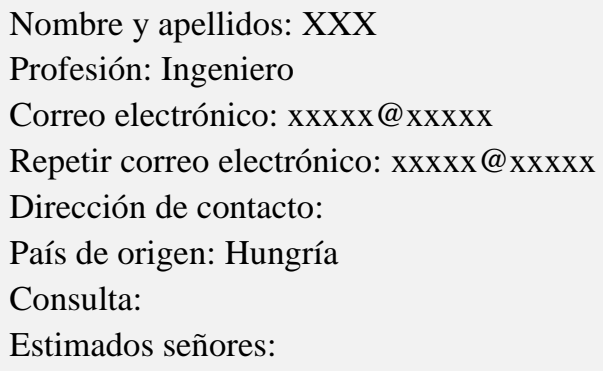

Aunque los diccionarios y otras obras académicos no recogen, se observa en la lengua coloquial representada en escritura el uso de SUPER (o SÚPER), ARCHI, MEGA, RECONTRA como intensificadores, precediendo directamente a las formas verbales, como por ejemplo: "Te SUPER quiero", "Te RECONTRA amo".

En tales casos, si no me equivoco, las palabras citadas funcionan, semánticamente, como adverbios, sin embargo no lo son, puesto que tampoco es correcto decir *Te muy/mucho quiero o *Te demasiado amo. Por tanto me parece que son realmente prefijos separables con función adverbial intensificadora, precisamente porque se intercalan entre el pronombre enclítico y la forma verbal. Pero si son prefijos, deberían escribirse unido a la forma verbal: "Te SUPERquiero" y "Te RECONTRAamo". No obstante, las formas escritas separadamente son muchísimo más extendidas, lo que, en mi opinión, quizás sea porque en el lenguaje hablado se pronuncian con acento léxico.

Quisiera saber si estoy en lo cierto y si la Academia acepta estos usos como correctos. De antemano, muchas gracias por su respuesta y reciban un cordial saludo desde Hungría.

\section{RESPUESTA:}

Estimado Sr. XXX:

En relación con su consulta, nos complace remitirle la siguiente información:

En realidad, archi-, super-, mega- o recontra- son, en los usos que usted menciona, prefijos gradativos que indican el grado alto de lo que se predica. Algunos de ellos han dado lugar a formaciones ya asentadas en la lengua, como archi- (archiconocido), extra- (extrafino), hiper- (hiperactivo), super(superelegante), ultra- (ultraconservador), re-(relimpio), requete-(requetebueno), etc.

Se ha observado un incremento muy notable de estos derivados en el español juvenil del área rioplatense (y, con menor intensidad, en la chilena), donde se extiende a adjetivos con los que resulta inusitado en otras áreas (piénsese, solo con el prefijo re-, en formaciones como redenso, relindo, reloco, regenio), a adverbios (rebién, remal, relejos, retarde, redespacio), así como a verbos (regustar 'gustar mucho', redoler 'doler mucho', requerer 'querer mucho', etc.). 
Cómo citar este artículo: Battaner Arias, Paz y López Ferrero, Carmen (2019). "La flexibilidad como propuesta normativa a la diversidad lingüística y dialectal. Perspectivas desde la Real Academia Española (RAE)”. Journal of Spanish Language Teaching 6 (2), pp. 106-118.

DOI: https://doi.org/10.1080/23247797.2019.1668180

A esta pauta pertenecen las secuencias que usted menciona en su consulta: Te superquiero, Te recontraamo, etc., de carácter expresivo y coloquial que, por ser formas prefijas, deben escribirse pegadas a la base léxica, en este caso verbal.

Figura 4. Consulta sobre morfología léxica.

\author{
Nombre y apellidos: XXX \\ Nivel de estudios: Elementales \\ Profesión: Estudiante \\ Correo electrónico: xxxxx@xxxxx \\ Repetir correo electrónico: xxxxx@xxxxx \\ Dirección de contacto: \\ País de origen: Brasil \\ Consulta: \\ Soy estudiante de la lingua española, me gustaria de saber cuál es la pronunciación correcta de la letra \\ $\mathrm{y}$ ? \\ Esta duda surge en el clase de español con profesor. Es correcto se hablar i griega o ye? \\ Muchas gracias y perdón por los errores de espanõl.
}

\title{
RESPUESTA:
}

Estimado Sr. XXX:

Aunque las obras académicas más recientes señalaban como preferente el nombre tradicional de $i$ griega, para la letra $y$, el nombre común recomendado hoy para esta letra en todo el dominio hispanohablante es ye por ser más simple y distinguirse directamente, sin necesidad de especificadores, del nombre de la vocal $i$.

No obstante, tal como se indica en el texto de la Ortografía de la lengua española (2010), publicada por la RAE y la ASALE, las recomendaciones en lo referente a los nombres de las letras del abecedario, en particular la recomendación del nombre ye para la letra $y$, no implica interferencia en la libertad que tiene cada hablante o cada país de seguir aplicando a las letras los términos que venían usando, algunos de ellos con larga tradición de siglos, como es el caso del nombre $i$ griega.

Reciba un cordial saludo.

Departamento de «Español al día»

Real Academia Española

Figura 5. Consulta sobre cuestiones ortográficas

El análisis detallado de las distintas consultas recibidas por hablantes no nativos permite comprobar que la mayoría son de estudiantes (orientales, brasileños) y de profesores (de países asiáticos como China, Corea o Japón, o americanos no hispanos de Brasil, EE. UU., de otros países europeos, como Francia y Alemania); también de otras profesiones (traductores, ingenieros). Se plantean dudas sobre aspectos de la norma que tienen que ver con la ortografía, con la gramática, con el léxico. En todas las respuestas que ofrece la RAE se tiene muy en cuenta la naturaleza policéntrica del español; destacan la remisión a la NGLE (2009) y las consideraciones de diversidad lingüística y dialectal en las respuestas que se ofrecen, como se observa en los dos ejemplos seleccionados, que representan casos que se abordan desde el "uso general hispánico", panhispánico, por tanto. Entre el núcleo estándar común y la modalidad del entorno tiene que haber flexibilidad como promoción de la diversidad lingüística y dialectal que se impulsa desde la RAE. La gran atención que despierta esa norma flexible se puede seguir en 
Cómo citar este artículo: Battaner Arias, Paz y López Ferrero, Carmen (2019). "La flexibilidad como propuesta normativa a la diversidad lingüística y dialectal. Perspectivas desde la Real Academia Española (RAE)". Journal of Spanish Language Teaching 6 (2), pp. 106-118.

DOI: https://doi.org/10.1080/23247797.2019.1668180

algunos de los tuits que continuamente llegan y se responden por el mismo servicio del Español al día (véase: https://bit.ly/2W0Vg2U).

La misma promoción dialectal está presente en la base de datos que constituye el CORPES XXI, un corpus de referencia de la RAE, que incorpora 25 millones de formas por año, con una distribución general de $30 \%$ para textos españoles y $70 \%$ para textos americanos, entre los que se incluyen también del español de EE. UU. El soporte de los textos es fundamentalmente escrito (un $90 \%$, frente a un $10 \%$ de lengua oral), procedentes de libros (40\%), publicaciones periódicas $(40 \%)$, material de internet $(7,5 \%)$ y miscelánea $(2,5 \%)$.

El reto en este siglo XXI será profundizar en el conocimiento del uso que se hace del español en la red universal; ya se planea introducir conversaciones y tuits mantenidos en teléfonos inteligentes en el CORPES XXI, lo que permitirá aconsejar en el uso de los nuevos formatos.

\section{El panhispanismo de la RAE en la educación y en la sociedad}

Con el paso al siglo XXI, en el campo de la enseñanza de ELE emerge en España la necesidad de responder la pregunta de si los estudiantes han de conocer otras variedades y principalmente las americanas (veáse, por ejemplo, los trabajos recogidos ya en Martín Zorraquino y Díez Pelegrín 2000, o las reflexiones de Moreno-Fernández 2000, entre muchas otras). En estos trabajos Martín Zorraquino (2000) entroncaba la reflexión con la Escuela Española de Filología, siempre bajo la tutela de don Ramón Menéndez Pidal aun, planteando las preguntas clave: "¿hasta qué punto debe ajustarse el profesor de español a extranjeros a una norma estándar? ¿En qué medida debe reflejar su propia forma de hablar al enseñar a sus alumnos? ¿Cuántos tipos de variedades hispánicas deben enseñarse?” $(2000,9)$.

En relación con los manuales de ELE, Grande Alija (2000) analizó allí las series de cuatro libros distintos, para concluir que "Realizados desde la perspectiva de España han incorporado de un modo creciente información sobre el estado de la lengua en América" (Grande Alija 2000, 400). Destaca en estos materiales el esfuerzo considerable en incluir la presencia de lo americano en sus distintas vertientes. En algunos de los manuales más recientes (2016-2018) publicados en España, se observa esta atención a la diversidad dialectal especialmente en los textos orales y audiovisuales (vídeos de películas "hispanas", por ejemplo, propuestos para trabajar la comprensión auditiva): se seleccionan muestras de entonaciones y acentos de las variantes del español en libros como Bitácora. Nueva edición, 1, 2 y 3 (Sans et al. 2016, 2017), Experiencias 1, 2 y 3 (Alonso, Alonso y Ortiz 2018) o Agencia ELE 1 (Amenós, Gil-Toresano y Soria 2018), Agencia ELE 2 (Gil-Toresano et al. 2017) y Agencia ELE 3 (Fernández et al. 2018), por ejemplo. La atención a las variantes léxicas o morfosintácticas son menos manifiestas en los publicados en España y no suele ser un trabajo sistemático. Este trabajo sistemático se recoge en materiales específicos elaborados con tal fin, como la colección Aula América 1 (Ariza et al. 2018) y América 2 (Ariza et al. 2019).

Los que se editan en otros países, en cambio, destacan más explícitamente estas diferencias en los planos léxico y gramatical: así se hace, por ejemplo, en el manual de ELE Con dinámica. Competencias y estrategias (2009), destinado a estudiantes alemanes, publicado en Stuttgart por la editorial Klett/Difusión; o en los materiales que se elaboran en las instituciones de Hispanoamérica que cuentan con programas de formación en ELE, como la UNAM en México o el Instituto Caro y Cuervo en Colombia. El manual Con dinámica, por ejemplo, introduce en las primeras páginas la siguiente explicación para un estudiante principiante (A1):

En América Latina y Andalucía se dice: Y ustedes, ¿qué hacen en el tiempo libre?
En el resto de España se dice:

Y vosotras, ¿qué hacéis en el tiempo libre? 
Cómo citar este artículo: Battaner Arias, Paz y López Ferrero, Carmen (2019). "La flexibilidad como propuesta normativa a la diversidad lingüística y dialectal. Perspectivas desde la Real Academia Española (RAE)". Journal of Spanish Language Teaching 6 (2), pp. 106-118.

DOI: https://doi.org/10.1080/23247797.2019.1668180

La sensibilización temprana en niveles tan básicos, un A1, impide matizar más en las variantes morfológicas del verbo correspondientes a estos usos dialectales de los pronombres ustedes y vosotros, pero es un pequeño signo de atención.

En cuanto a las gramáticas pedagógicas, con explicaciones y ejercicios para estudiantes de ELE, también el lugar en que han sido publicadas determina el grado de detalle dedicado a incidir en las diferencias morfológicas y sintácticas según la variedad dialectal del español. Por ejemplo, en Lunn y DeCesaris (1992, $20062^{\mathrm{a}}$ ed.), en el Instructor's Manual se señala:

"In Más Práctica students are frequently asked to interview native speakers of Spanish. We believe such exercises are important for students at this stage because they give them an opportunity to use the Spanish and to see that the language is a series of structures in constant evolution." (Lunn y Decesaris 1992, 3)

También presenta esta gramática en el manual para el estudiante la diferenciación dialectal entre los pronombres sujetos vos, vosotros y ustedes:

"Los pronombres vos y vosotros aparecen aquí entre paréntesis porque no se utilizan en todos los dialectos del español. Vos se utiliza en lugar de tú o como una variante íntima de tú en aproximadamente $40 \%$ de los dialectos americanos. En muchos de estos dialectos, sin embargo, el voseo se limita a la lengua hablada, y por eso el pronombre tú sigue considerándose el estándar. Vosotros es el plural de tú en la gran mayoría de los dialectos de España; en América, el plural de tú (o vos) es ustedes." (Lunn y Decesaris 1992, 84)

Muchos másteres que forman en la especialización de profesor de ELE programan una asignatura específica sobre las variedades del español. Como consecuencia, los manuales destinados a esta formación de profesorado incluyen un capítulo (el primero habitualmente) sobre "el español en el mundo" (véase el volumen específico de Santiago Guervós y Fernández González 2017, o el más general de Muñoz-Basols et al. 2017).

En este sentido, un plano en el que es necesario avanzar es el de la pragmática y su diversidad dialectal. La pragmática variacionista y la enseñanza del español ELE es un campo en desarrollo en la actualidad, con muchos trabajos ya publicados sobre aspectos pragmáticos concretos de cada variedad y su contraste con otras. Falta por disponer de un repertorio más amplio de fenómenos descritos desde una perspectiva panhispánica, tal y como se ha trabajado con el léxico, la gramática o la pronunciación.

Hoy los medios de comunicación popularizan las variedades de la lengua española. Televisión, vídeos, series, mensajes de voz, "regalos" en WhatsApp fluyen por todos los dispositivos y todo el mundo es consciente de que la lengua varía de un sitio a otro. Es esta una circunstancia que se ha de tener en cuenta en los materiales de enseñanza; ya no es el aislamiento al que se estaba sometido antes de 1975.

\section{Conclusiones}

Finalizamos esta reflexión sintetizando las cuestiones que hemos abordado y apuntando algunos de los retos a los que se enfrenta el panhispanismo desde la Real Academia Española en la tercera década de este siglo XXI. Se ha rastreado tanto la voluntad panhispánica como los logros alcanzados en esta orientación por los recursos académicos. Por ser estos muchos y depender algunos, como el $D L E$, de redacciones anteriores al siglo XXI, es posible encontrar alguna inconsistencia, pero, una vez señalada, se advierte voluntad de consignar lo que se pueda documentar bien.

A partir de los datos aquí presentados, el seguimiento queda manifiesto y materializado en las consultas abiertas que ofrece la página web de la RAE tanto de diccionarios, gramática y corpus, como también en el servicio Español al día. La autoridad de la RAE, hoy acompañada 
Cómo citar este artículo: Battaner Arias, Paz y López Ferrero, Carmen (2019). "La flexibilidad como propuesta normativa a la diversidad lingüística y dialectal. Perspectivas desde la Real Academia Española (RAE)". Journal of Spanish Language Teaching 6 (2), pp. 106-118.

DOI: https://doi.org/10.1080/23247797.2019.1668180

siempre de la ASALE, se advierte como orientadora, al abogar por la flexibilidad como propuesta normativa. El alcance y el acierto de la orientación panhispánica descrita parece que se desarrolla convenientemente y que lo propuesto por la Real Academia Española tiene acogida en los materiales de enseñanza, en la formación de profesores y se hace presente en los varios medios de comunicación entre los hablantes, quienes, cada día más, traspasan los límites del localismo cercano y se manifiestan colectiva e individualmente en este mundo nuestro globalizado; de todo lo cual las publicaciones didácticas se hacen eco.

El seguimiento de lo que presenta la actividad de la enseñanza del español, tanto como lengua nativa, o como lengua segunda o extranjera, no debe quedar solo en una constatación de la atención que recibe. Convendría que fuera también objeto preferente de la RAE y de la ASALE. El español interesa hoy por el número de hablantes que se reconocen como de la misma lengua, por la situación geopolítica de los países en que se habla, por la vitalidad y originalidad de sus producciones culturales y artísticas. Las necesidades que la actividad de su enseñanza levanta pueden ser también valoradas como oportunidades para su crecimiento en unidad, con la flexibilidad que le otorga su capacidad de ampliación y enriquecimiento, representada por las modalidades dialectales y locales auténticas.

\footnotetext{
Notas

${ }^{1}$ Este proyecto se presentó en el II Simposio del Programa Interamericano de Lingüística y Enseñanza de Idiomas (Bloomington, Indiana, 1964), consolidado en el IV Congreso de la Asociación de Academias de la Lengua (Buenos Aires 1966), que aprobó el proyecto.

${ }^{2}$ Citamos las palabras iniciales de D. José Luis Vega, director de la Academia Puertorriqueña, en el XII Congreso de la Asociación de Academias, recogidas en López Morales $(2016,728)$.

${ }^{3}$ La UNIDRAE se creó en 2011 para recibir las propuestas y sugerencias externas relacionadas con el Diccionario de la lengua española. La UNIDRAE responde acusando recibo inmediato de la llegada de la propuesta, "que será objeto de un estudio exhaustivo posterior."

${ }^{4}$ Agradecemos a los servicios del Ilex y de Español al día, tanto a sus directores académicos, como a sus directoras técnicas doña Elena Zamora y doña Elena Hernández, las muestras enviadas. Estas actividades no solo permiten a la RAE "hacer pedagogía y promover un uso correcto del español y el conocimiento de la norma", sino que también son "una fuente de información valiosísima sobre qué preocupa a los hablantes y también sobre cambios lingüísticos y nuevas palabras", neologismos y extranjerismos.
}

\section{Bibliografía}

Alonso, E., G. Alonso y S. Ortiz. 2018. Experiencias 1, 2 y 3. Libro del alumno. Madrid: Edelsa.

Amenós, J., M. Gil-Toresano e I. Soria. 2018. Agencia ELE. Nueva edición 1. Libro de clase, Madrid: SGEL.

Ariza, E., J. Corpas, J., A. Garmendia, G.V. Nieto y G. Molina y C. Soriano. 2019. Aula América 2. Ed. Difusión

Ariza, E., J. Corpas, J., E. García, A. Garmendia, G.V. Nieto y G. Molina. 2018. Aula América 1. Ed. Difusión

Bello, A. 1847 [1988]. Gramática de la lengua castellana destinada al uso de los americanos. Con notas de Rufino José Cuervo; estudio y edición de Ramón Trujillo. 2 vols. Madrid: Arco/Libros.

Cruzat, A. 2018. "Oye, Siri, ¿de quién es la voz de tu versión española". ArchiLetras 1: 83-86.

de Santiago Guervós, J. y J. Fernández González. 2017. Fundamentos para la enseñanza del español como 2/L. Madrid: Arco/Libros.

Fernández, C., F. Genta, J. Lahuerta, C. Moreno, J. Ruiz y J. Sanmartín. 2018. Agencia ELE. Nueva edición 3. Libro de clase, Madrid: SGEL.

Gil-Toresano, M., I. Soria, A. Duque, S. Espiñeira, N. de la Torre y A. Vañó. 2017. Agencia ELE. Nueva edición 2. Libro de clase, Madrid: SGEL.

Grande Alija, F. J. 2000. "La diversidad del español a través de los manuales de E/LE. ¿Qué lengua enseñan?”. En ¿Qué español enseñar? Norma y variación lingüísticas en la enseñanza del español 
Cómo citar este artículo: Battaner Arias, Paz y López Ferrero, Carmen (2019). "La flexibilidad como propuesta normativa a la diversidad lingüística y dialectal. Perspectivas desde la Real Academia Española (RAE)”. Journal of Spanish Language Teaching 6 (2), pp. 106-118.

DOI: https://doi.org/10.1080/23247797.2019.1668180

a extranjeros, Actas del XI Congreso Internacional de ASELE, Zaragoza, 13-16 de septiembre de 2000, eds. M. A. Martín Zorraquino y C. Díez Pelegrín, 393-402. ASELE: Universidad de Zaragoza.

Lope Blanch, J. M. 1973. Cuestionario para el estudio coordinado de la norma lingüística culta de Iberoamérica y de la Península Ibérica, tomo I (Fonética y Fonología). Madrid: CSIC.

Lope Blanch, J. M. 1986. Estudio del español hablado culto. Historia de un proyecto. México: UNAM.

López Morales, H. 2016. Historia de la Asociación de Academias de la Lengua Española Madrid: ASALE.

Lunn, P. V. y J. A. DeCesaris. 2006. Investigación de gramática. Student's Handbook e Instructor's Manual, $2^{\text {a }}$ ed. Boston: Heinle Publishers.

Martín Zorraquino, M. A. 2000. "Norma y variación lingüísticas en la enseñanza de E/LE”. En ¿Qué español enseñar? Norma y variación lingüísticas en la enseñanza del español a extranjeros, Actas del XI Congreso Internacional de ASELE, Zaragoza, 13-16 de septiembre de 2000, eds. M. A. Martín Zorraquino y C. Díez Pelegrín, 7-11. ASELE: Universidad de Zaragoza.

Martín Zorraquino, M. A. y C. Díez Pelegrín, eds. ¿Qué español enseñar? Norma y variación lingüísticas en la enseñanza del español a extranjeros, Actas del XI Congreso Internacional de ASELE, Zaragoza, 13-16 de septiembre de 2000. ASELE: Universidad de Zaragoza.

Moreno-Fernández, F. 2000. Qué español enseñar. Madrid: Arco/Libros.

Muñoz-Basols, J., N. Moreno, I. Taboada y M. Lacorte. 2017. Introducción a la lingüística hispánica actual: teoría y práctica. Londres y Nueva York: Routledge.

RAE. 2018. Libro de estilo de la lengua española, según la norma panhispánica. Madrid: Espasa.

RAE y ASALE. 2005. Diccionario panhispánico de dudas. Madrid: Santillana. Disponible en: http://www.rae.es/recursos/diccionarios/dpd

RAE y ASALE. 2009. Nueva gramática de la lengua española. 2 vols. Madrid: Espasa. Disponible en: http://www.rae.es/recursos/gramatica/nueva-gramatica

RAE y ASALE. 2010a. Nueva gramática de la lengua española. Manual. Madrid: Espasa. Disponible en: http://www.rae.es/

RAE y ASALE. 2010b. Ortografía de la lengua española. Madrid: Espasa.

RAE y ASALE. 2011. Las voces del español. Tiempo y espacio. DVD. Madrid: Espasa.

RAE y ASALE. 2011. Nueva gramática de la lengua española. Fonética y fonología. Madrid: Espasa.

RAE y ASALE. 2014. Diccionario de la lengua española. 23. a ed. Madrid: Espasa. Versión 23.2. Disponible en: https://dle.rae.es/?w=diccionario

Sans, N., E. Martín Peris, A. Garmendia y E. Conejo. 2016-2017. Bitácora 1, 2 y 3. Nueva edición. Libro del alumno. Barcelona: Difusión.

Sans, N., E. Martín Peris, J. Muntal, R. Acquaroni y E. Conejo. 2018. Bitácora 4. Nueva edición. Libro del alumno. Barcelona: Difusión.

Seco, M. 1961 [2011]. Diccionario de dudas y dificultades de la lengua española. 11 ${ }^{\mathrm{a}}$ ed. Madrid: Espasa. 